\title{
Cellular Physiology

\section{Lentivirus-mediated RNAi Targeting CREB Binding Protein Attenuates Neointimal Formation and Promotes Re-endothelialization in Balloon Injured Rat Carotid Artery}

\author{
Jian Yang ${ }^{1, *}$, Hong Jiang ${ }^{1}$, Si-si Chen ${ }^{1, *}$, Jing Chen ${ }^{1}$, Wan-qiang $\mathrm{Li}^{2}$, \\ Sheng-kai $\mathrm{Xu}^{1}$ and Ji-chun Wang ${ }^{1}$
}

${ }^{1}$ Department of Cardiology, Renmin Hospital of Wuhan University, Wuhan 2Department of Urology, Renmin Hospital of Wuhan University, Wuhan. ${ }^{*}$ These authors contributed equally to this study

\section{Key Words}

Gene therapy $\cdot$ Lentivirus $\cdot$ Neointimal formation • Endothelial regrowth

\begin{abstract}
Background/Aims: Lentiviral vectors provide a promising strategy for the treatment of cardiovascular diseases, owing to their ability to govern efficient and durable gene transfer. However, relatively few studies have been addressed on restenosis after balloon or stent associated arterial injury. We previously found that CREB binding protein (CBP), a powerful transcriptional coactivator, regulated cell proliferation and apoptosis in vascular endothelial and smooth muscle cells. Therefore, we investigated whether inhibition of CBP by lentivirus-mediated small interfering RNA can reduce neointimal formation after arterial injury. Methods: The carotid arteries from Sprague-Dawley rats were injured by balloon catheter, followed by incubating with $100 \mu$ l lentivirus expressing CBP or negative control (NC)-specific short hairpin RNAs (shRNAs) or PBS solution for 30 minutes. The
\end{abstract}

\section{KARGER}

Fax +4161306 1234 E-Mail karger@karger.ch www.karger.com
(C) 2010 S. Karger AG, Basel

$1015-8987 / 10 / 0263-0441 \$ 26.00 / 0$

Accessible online at: www.karger.com/cpb rats were euthanized for real-time PCR, Western blot, immunohistochemical staining, and morphometric analysis at 4 weeks after balloon injury and in vivo gene transfer. Results: Lentiviral shRNA targeting CBP markedly reduced CBP expression. Moreover, CBP siRNA showed potent inhibition on balloon injuryinduced Nuclear factor kappaB (NF-kB) acetylation. Compared with controls, the significant decrease of neointimal formation by CBP siRNA was accompanied by reduced cell proliferation in the neointima of injured arteries. However, no changes in medial area were observed among these different groups. Interestingly, endothelial cell marker CD31 immunostaining and morphometric analysis both showed that CBP knockdown significantly accelerated reendothelialization. Conclusions: These findings suggest that CBP is involved in the control of neointimal formation and re-endothelialization via regulating NF- $\kappa \mathrm{B}$ acetylation. Lentivirus-mediated CBP silencing may represent a novel therapeutic approach for the prevention of restenosis after vascular interventions.

Copyright @ 2010 S. Karger AG, Basel

Hong Jiang

Department of Cardiology, Renmin Hospital of Wuhan University

Wuhan 430060, Hubei Province (China)

Tel. +86-027 88041911, Fax +86-027 88040334

E-Mail jianghong_rm@163.com 


\section{Introduction}

Percutaneous coronary intervention (PCI) is a widely used technique for the treatment of coronary heart diseases $[1,2]$; however, the subsequent restenosis may reduce the therapeutic effects and remain a serious clinical problem [3]. A large body of clinical and experimental studies have demonstrated that neointimal hyperplasia contributing to restenosis is triggered by complex biological responses, including inflammation, thrombosis, cellular proliferation, and extracellular matrix production [4-6]. Among these multiple factors, media-to-intima migration and proliferation of vascular smooth muscle cells (VSMCs) is the most critical step in the pathogenesis of neointimal formation $[7,8]$.

In recent years, advances in antiproliferative pharmacologic agents and drug-eluting stents have dramatically reduced the incidence of restenosis [9-11]. Nevertheless, safety concerns have been raised that these antiproliferative therapies may also be associated with delayed re-endothelialization, hypersensitivity reactions, and late stent thrombosis [12,13]. Therefore, novel strategies to prevent restenosis, which could selectively suppress VSMCs proliferation and enhance endothelialization are urgently needed. Encouragingly, gene therapy is emerging as a potential treatment option for patients with cardiovascular diseases [14-17].

CREB binding protein (CBP) was identified based on its ability to interact with the cAMP-regulated transcription factor CREB [18]. In fact, CBP and its close homologue p300, are widely expressed and play pivotal roles in all known cellular programs, such as cell growth, differentiation and apoptosis [19-21]. Accumulating evidence indicates that CBP not only possesses histone acetyltransferase activity [22,23], but also acts as a key transcriptional coactivator linking various sequencespecific transcription factors such as NF- $\mathrm{KB}$ [24], AP-1 [25] and p53 [26], to regulate downstream genes expression [27]. Thus, the combination of these multiple functions could make it to be involved in the regulation of different signalling pathways, which have been attracting the attention of the scientific world.

Previous work from our laboratory has demonstrated that silencing of CBP gene expression by RNA interference potently inhibited thrombin-induced VSMCs proliferation in vitro [28]. Moreover, CBP was shown to support vascular endothelial cells (VECs) activation and apoptosis. However, the expression of CBP in the artery wall and its possible role in the development of intimal hyperplasia after vascular injury have not yet been determined.

In the present study, to test the hypothesis that CBP might participate in neointimal formation after balloon injury in vivo, we used lentivirus infection to deliver a specially designed small interfering RNA (siRNA) targeting CBP into a rat carotid arterial balloon-injury model and evaluated the effects of CBP gene silencing on neointimal hyperplasia. We demonstrated for the first time that lentiviral shRNA against CBP could efficiently attenuate neointimal formation without delaying reendothelialization, and the mechanism is involved with downregulation of NF- $\kappa B$ acetylation. These results indicate that inhibition of CBP may provide a prospective strategy for the treatment of vascular diseases.

\section{Materials and Methods}

\section{Construction and production of lentiviral vectors}

Four siRNA sequences against the rat CBP gene (GenBank Accession No. NM 133381) were designed and synthesized by Genechem (Shanghai, China). A scrambled siRNA was used as a negative control. Sense siRNA sequences were as follows: siCBP 1, TAG TAA CTC TGG CCA TAG C; siCBP 2, GCAAAC AGA GCA TGG TCA A; siCBP 3, GAT GAT GGA AGA GGA TTT A; siCBP 4, CCAATG GAA GTA GAA GAAA; siNC, TTC TCC GAA CGT GTC ACG T. ShRNAs were inserted into the HpaI and XhoI restriction enzyme sites of pFU-GW-iRNA lentiviral vector that driven by the U6 promoter and carrying the green fluorescent protein reporter gene, respectively. All constructs were confirmed by DNA sequencing. Among four CBP siRNAs examined, siCBP 2 was selected as the best performing siRNA for use in the next study. Lentivirus encoded shRNA against CBP and control were produced by cotransfecting $293 \mathrm{~T}$ cells with the help of lipofectamine 2000 (Invitrogen) according to standard protocols. The Virus titers, measured in $293 \mathrm{~T}$ cells transducing units per milliliter $(\mathrm{TU} / \mathrm{ml})$, were approximately $2 \times 10^{9} \mathrm{TU} / \mathrm{ml}$.

Rat carotid artery balloon injury model and lentiviral transduction

Forty-eight male Sprague-Dawley rats weighing 350 to $400 \mathrm{~g}$ (Wuhan, China) were randomly divided into four equal groups $(n=12)$. The animals were anesthetized with pentobarbital (30 $\mathrm{mg} / \mathrm{kg}$ intraperitoneal) and subject to balloon catheter injury of the left common carotid artery as reported previously [29]. In brief, After intravenous injection of $100 \mathrm{U} /$ $\mathrm{kg}$ of heparin sodium, the left common, external and internal carotid arteries were exposed. The external carotid artery was partially cut at about $2 \mathrm{~mm}$ from the arterial bifurcation with microscissors. Meanwhile, blood flow was temporarily interrupted by ligation of the common and internal carotid arteries using microvascular clips. A balloon angioplasty catheter (balloon diameter $1.5 \mathrm{~mm}$, balloon length $20 \mathrm{~mm}$, Medtronic) was introduced through the external carotid cut

Yang/Jiang/Chen/Chen/Li/Xu/Wang 
into the common carotid artery. The balloon was then inflated and passed thrice with rotation to ensure uniformity of the extent of balloon injury. For lentiviral transduction, A $100 \mu 1$ solution of lenti-CBP siRNA-GFP $\left(1 \times 10^{8} \mathrm{TU} / \mathrm{ml}\right)$, lenti-NC siRNA-GFP $\left(1 \times 10^{8} \mathrm{TU} / \mathrm{ml}\right)$ or PBS were respectively infused into the injured common carotid artery segment (about $2 \mathrm{~cm}$ in length) isolated by the two microvascular clips, and incubated for $30 \mathrm{~min}$. After removal of this solution, the external carotid artery was ligated and blood flow through the common and internal carotid arteries was restored. The rats were euthanized at 4 weeks after balloon injury and lentiviral infection, and the tissues were harvested for specific protocols. Sham-operated controls underwent the same procedures, except balloon insertion. The experimental procedures and animal care were approved by the Animal Care and Use Committee of Wuhan University, and conformed to the Guide for the Care and Use of Laboratory Animals by the National Institutes of Health (NIH Publication No. 80-23).

\section{Real-time RT-PCR}

Total RNA was extracted from the carotid arteries with Trizol reagent (Invitrogen). Reverse transcription and real-time PCR were performed as described previously [28]. Total RNA was reverse-transcribed into cDNA, and real-time PCR was performed on the ABI Prism 7500 sequence detection system (PE Applied Biosystems) by using SYBR Green Realtime PCR Master Mix kit (TaKaRa, Japan) in accordance with the manufacturer's instructions. GAPDH was used for normalization, and data were analyzed using the $2^{-\Delta \Delta C t}$ method. Primer sequences were as follows: CBP (NM_133381), forward: 5'-TGG AGA AGC ACAAGG AGG TC-3', reverse:5'-GCG GCG TAA GGA AGA GA AC-3'. GAPDH (NM_017008), forward: 5'TTC AAC GGC ACA GTC AAG G-3', reverse: 5'-CTC AGC ACC AGC ATC ACC-3'.

\section{Immunoprecipitation and Western blot analysis}

$\mathrm{CBP}$ and NF- $\mathrm{NB}$ expression was examined by Immunoprecipitation and Western blotting in injured vessels transduced with or without lentiviral vectors. Rat common carotid arteries were homogenized with ice-cold lysis buffer, and then prepared for total and nuclear protein extraction as described [30]. The protein concentration was measured by the BCA protein assay (Pierce). For immunoprecipitation, anti$\mathrm{CBP}$ or anti-NF- $\kappa \mathrm{B}$ p65 antibody (Santa Cruz) was coupled to protein A/G-agarose (Santa Cruz) beads and incubated with equal amounts of arterial protein overnight at $4^{\circ} \mathrm{C}$. After the beads were washed, the immunoprecipitates were separated by SDS-PAGE on $6 \%$ polyacrylamide gels and then transferred to nitrocellulose membranes. Blots were probed with anti-CBP, anti-NF- $\kappa$ B p65, anti-Acetyl (Lys310)-NF- $\mathrm{B}$ p 65 (CST) or antiGAPDH antibody (Santa Cruz) as an internal control, respectively. After washing, the protein bands were incubated with horseradish peroxidase-conjugated secondary antibodies and processed for ECL (Pierce) according to the manufacturer's instructions.

\section{Morphology}

Four weeks after the operation, the injured and control

CBP Silencing Inhibits Neointimal Formation carotid arteries were harvested, fixed in 4\% paraformaldehyde, and then embedded in paraffin. For morphologic analysis of neointimal formation, five round cross-sections ( $4 \mu \mathrm{m}$ thickness) were cut from the approximate middle of the artery, stained with hematoxylin-eosin, photographed, and analyzed using ImagePro Plus 5.0 professional image analysis software. The intimal and medial cross-sectional areas of the carotid arteries were measured, and the intima/media ratios were also calculated.

\section{Immunohistochemistry}

Immunohistochemical staining was performed as we previously described [31]. Briefly, the carotid sections were incubated with anti-proliferating cell nuclear antigen (PCNA; Santa Cruz) or anti-CD31 (Abcam) antibody overnight at $4{ }^{\circ} \mathrm{C}$, followed by incubation with a horseradish peroxidaseconjugated secondary antibody (Santa Cruz) for $60 \mathrm{~min}$ at room temperature. PBS substituted the primary antibodies were used as negative controls. At last, colour development was achieved with diaminobenzidine, and hematoxylin was applied as a counterstain prior to cover-slipping. CD31 could be considered as a marker of vessel endothelialization. PCNA was used to quantify the proliferative activity of cells at the balloon injury sites. Data are represented as a PCNA labeling index (LI), defined as the percentage of total cells within a given area positive for PCNA.

\section{Endothelial Regrowth}

Endothelial regrowth was evaluated by Evans blue staining. Rats received an intravenous injection of 1\% Evans blue dye solution ( $3 \mathrm{ml} / \mathrm{kg}$; Sigma) $30 \mathrm{~min}$ before sacrifice. Harvested left common carotid arterial segments were cut longitudinally and placed between glass microscope slides. The stained/unstained area was determined via planimetry by using image analyzer software (Image-Pro Plus 5.0). The reendothelialized section was defined as the area unstained with Evans blue dye. All specimen were calculated by the same observer, who was blinded to the treatment allocation. The results are expressed as a percent of the total surface area of the harvested arterial segment.

\section{Statistical analysis}

All statistical analysis was performed with Statistical Product and Service Solutions 13.0 software (SPSS 13.0). The data were presented as mean \pm SEM. Statistical comparison was carried out with three or more groups using one-way analysis of variance (ANOVA) followed by Student-NewmanKeuls post hoc tests. $P<0.05$ was considered significant.

\section{Results}

\section{Efficiency of lentiviral transfection into carotid artery}

To demonstrate the efficiency of siRNA delivery into the carotid arteries, lenti-CBP siRNA and lenti-NC siRNA were both labeled with GFP. Successful lentiviral transfection was evidenced by green fluorescence under 
confocal microscopy 4 weeks after injury (Fig.1). However, only weak chromogenic reaction of the elastic lamina was observed in untreated and PBS control groups.

\section{$C B P$ siRNA transfection in vivo decreased $C B P$} expression

CBP mRNA and protein were both detected in carotid arteries subjected to vascular injury. After 4 weeks of balloon injury, CBP mRNA expression was significantly upregulated 2.6-fold as compared to sham group without injury. Delivery of CBP siRNA into the carotid arteries after injury could markedly decrease CBP mRNA expression by $49.6 \%(P<0.05$, vs NC siRNA). NC siRNA had no inhibitory effect on the expression of CBP mRNA (Fig. 2A). As shown in Figure 2B, a similar pattern of expression was evident for CBP protein analyzed. Compared with lenti-NC siRNA group, lenti-CBP siRNA transfection greatly reduced CBP protein levels $(0.36 \pm 0.06$ vs $0.83 \pm 0.09, P<0.01)$ after balloon injury. However, there was no statistical difference between PBS and NC siRNA control groups.

\section{CBP siRNA suppressed neointimal hyperplasia}

Four weeks after balloon injury and lentiviral transfection, the degree of neointimal hyperplasia was evaluated morphologically and quantitatively (Fig. 3). Lenti-CBP siRNA treatment significantly reduced the neointimal area compared with lenti-NC siRNA and PBS controls $\left(0.108 \pm 0.008 \mathrm{~mm}^{2}\right.$ vs $0.252 \pm 0.016 \mathrm{~mm}^{2}$ or $0.238 \pm 0.022 \mathrm{~mm}^{2}, P$ both $<0.05$, Fig. 3B). The intima / media ratio was also markedly less in lenti-CBP siRNA transfected arteries $(0.706 \pm 0.062)$ than in lentiNC siRNA transfected $(1.497 \pm 0.137, P<0.05$, vs CBP siRNA) and PBS treated arteries $(1.483 \pm 0.136, P<0.05$, vs CBP siRNA) (Fig. 3D). No significant difference in the medial area was observed among all groups (Fig. 3C).

\section{Effect of $C B P$ siRNA on $N F-\kappa B$ acetylation}

To study whether CBP siRNA has any direct effect on NF- $\kappa \mathrm{B}$ acetylation, the Western blot analysis was performed. Our data showed balloon injury induced significant NF- $\mathrm{BB}$ p 65 acetylation and activation in the injured carotid arteries. Lenti-CBP siRNA treatment resulted in a $39.3 \%$ and $43.7 \%$ reduction of $N F-\kappa B$ p65 acetylation in lenti-NC siRNA transfected and PBS treated arteries, respectively $(P$ both $<0.05)$. However, CBP siRNA was not capable of suppressing its nuclear translocation caused by balloon injury $(P>0.05$, Fig. 4).

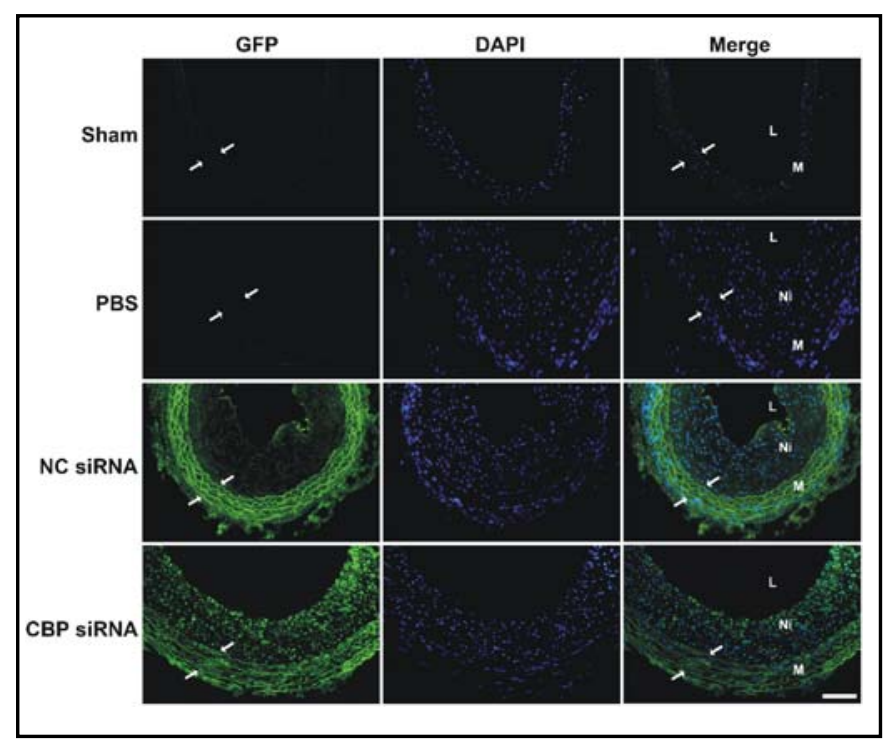

Fig. 1. Efficiency of lentivirus-mediated gene transfer at 4 weeks after balloon injury. Representative microphotographs of confocal microscopy in different groups. GFP and nuclei with DAPI were labelled by green and blue fluorescence respectively. Arrows indicate the elastic lamina; L, lumen; M, media; Ni, neointima. Scale bar represents $50 \mu \mathrm{m}$.

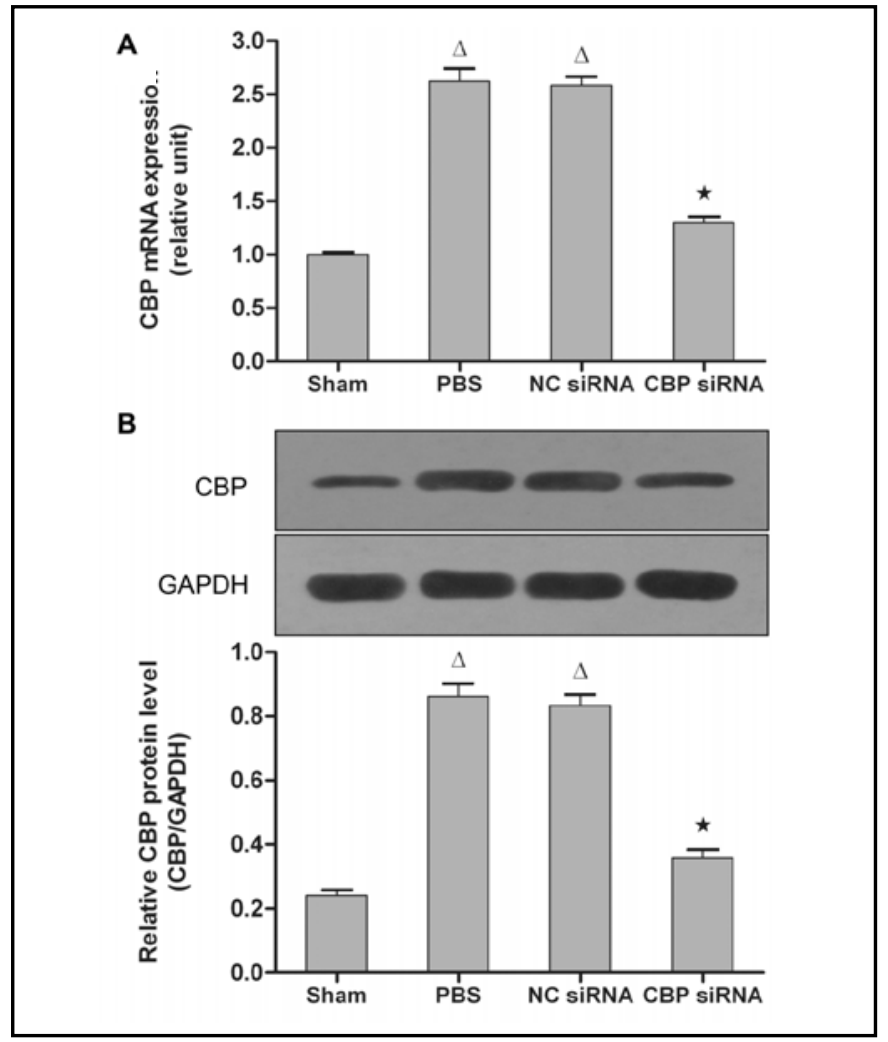

Fig. 2. Lentivirus-delivered CBP siRNA significantly inhibited the expression of CBP. (A) Real-time PCR showing efficient suppression of CBP mRNA in balloon injured arteries by siRNA. (B) Original representative western blots are reported in the upper panel and relative CBP protein level in the lower panel. Values are expressed as mean \pm SEM. $\mathrm{n}=6$ per group. ${ }^{\triangle} P<0.05$ vs. Sham group; ${ }^{\star} P<0.05$ vs. NC siRNA and PBS control groups.

Yang/Jiang/Chen/Chen/Li/Xu/Wang 


\section{Effect of CBP siRNA on cell proliferation}

Cell proliferation in the neointima and media of injured arteries was examined by immunostaining for PCNA. Treatment with lenti-CBP siRNA induced a significant reduction in the percentage of PCNA -positive cells in the neointima compared with lenti-NC siRNA and PBS treated control groups $(6.1 \pm 1.0 \%$ vs $14.9 \pm 4.1 \%$ and $17.3 \pm 5.2 \%$, respectively, $P$ both $<0.05$ ) (Fig. 5). However, there was no significant difference in the media among the three groups (data not shown).

\section{Effect of CBP siRNA on re-endothelialization}

To investigate if CBP gene silencing promotes endothelial growth at 4 weeks after balloon injury, the endothelial cell marker (CD31) immunostaining and Evans blue analysis were performed. As shown in Figure 6A, CD31 positive immunostaining was observed along the luminal surface of the vessel wall. The CD31+ cellcovered area to the total length of luminal surface in lentiCBP siRNA treated group was significantly greater than in the lenti-NC siRNA and PBS group $(P<0.05)$. Consistent with the immunostaining findings, Evans blue staining also demonstrated that CBP silencing could significantly accelerate re-endothelialization after catheter injury (Fig. 6B). Compared with lenti-NC siRNA and PBS controls, the extent of re-endothelialization was increased $43 \%$ and $26 \%$ in lenti-CBP siRNA treated group, respectively $(P<0.05)$.

\section{Discussion}

The present results clearly demonstrated that transduction of CBP shRNA into balloon-injured carotid arteries by lentivirus infection decreased CBP protein expression, and markedly suppressed neointimal formation. More importantly, CBP knockdown could enhance re-endothelialization after balloon catheter injury. These observations suggest that CBP might play an important role in the development and progression of neointimal hyperplasia after vascular injury, and lentivirus mediated gene therapy would be an attractive means for the prevention of vascular disease.

Current evidence has shown postangioplasty restenosis is still a major problem in spite of the development of drug-eluting stents $[9,10]$. Thus, gene therapy, an applied form of biotechnology, has gradually become feasible. Choosing the correct vectors and suitable genes is probably the most critical for gene therapy applications [32]. In our study, the lentiviral vector-

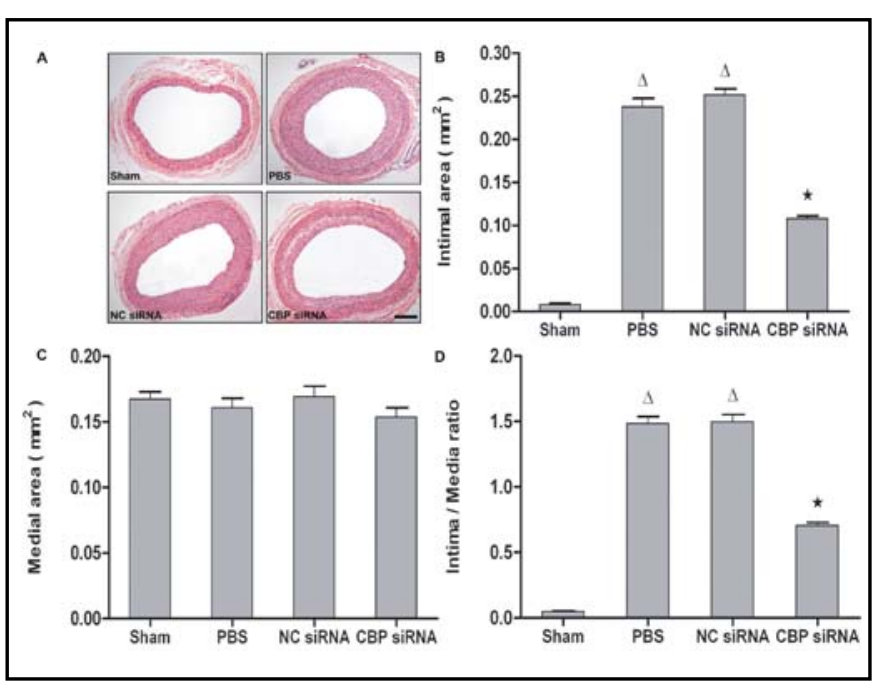

Fig. 3. Effects of CBP silencing on neointimal formation in injured carotid arteries. (A) Representative cross-sections of hematoxylin/eosin-stained carotid arteries. Scale bar represents $100 \mu \mathrm{m}$. Quantitative analysis of intimal area (B), medial area (C), ratio of intima to media (D) 4 weeks after balloon injury and gene delivery. Values are expressed as mean \pm SEM. $n=6$ per group. $\triangle P<0.05$ vs. Sham group; $\star P<0.05$ vs. NC siRNA and PBS control groups.

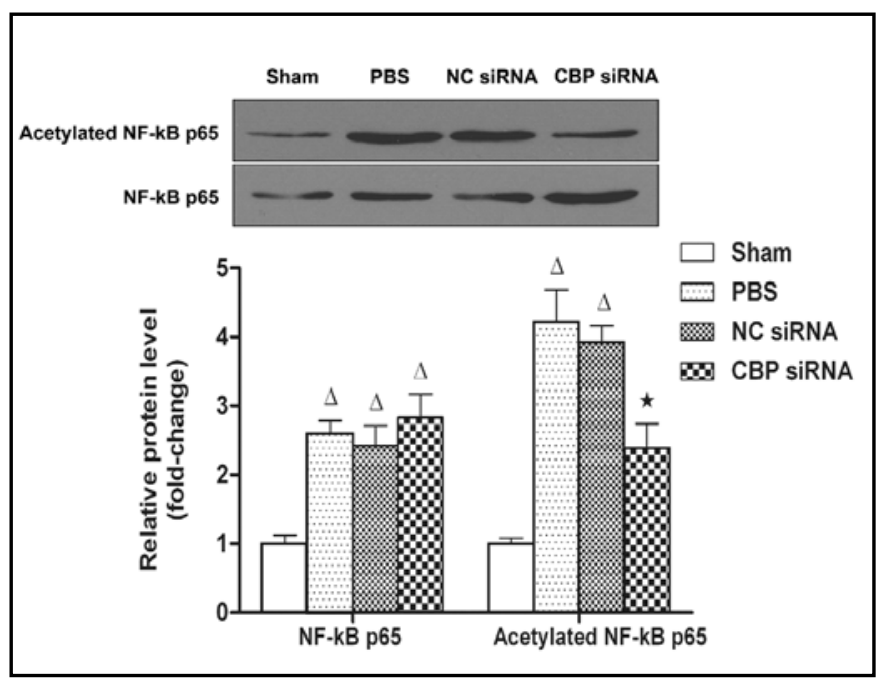

Fig. 4. CBP siRNA suppressed NF- $\kappa B$ p65 acetylation induced by balloon injury. Original representative western blots are reported in the upper panel and relative protein level in the lower panel. Values are expressed as mean \pm SEM. $n=6$ per group. $\triangle P<0.05$ vs. Sham group; ${ }^{\star} P<0.05$ vs. NC siRNA and PBS control groups.

mediated gene delivery system can efficiently deliver CBP siRNA into injured vessels, and that the effects are durable. At 4 weeks after lentiviral transfection, the strong green fluorescence was still detectable in all the arterial layers. In fact, a number of different viral systems such as retroviruses, adenovirus and adeno-associated virus 
Fig. 5. Anti-proliferative effects of CBP silencing. (A) Representative microphotographs of sections stained immunohistochemically for PCNA. Arrows indicate PCNAlabeled nuclei stained as dark brown. Ni, neointima. Scale bar represents $25 \mu \mathrm{m}$. (B) PCNA-positive nuclei were quantified as the percentage of total nuclei in the neointima. Data are expressed as mean \pm SEM. $n=6$ per group. ${ }^{\star} P<0.05$ vs. NC siRNA and PBS control groups.

have been commonly employed for in vitro and in vivo gene transfer [33, 34]. However, lentivirus as a subgroup of retroviruses, has several advantages over other viral or nonviral gene delivery systems [35]. It is able to infect both dividing and non-dividing cells, integrate into the chromosome of host cells and provide stable, long-term gene expression [36]. The above superior properties make lentiviral vector to be the optimal candidate for efficient cardiovascular gene therapy. We presume that lentivirusmediated long-lasting expression of gene in the vascular wall could compensate the limitation of other viral vectors mediated transient gene transfer. Of course, our data gave us enough confidence that the hypothesis was right.

In addition to an effective gene delivery system, appropriate target gene is the second important element for vascular gene therapy. Numerous studies have identified a lot of therapeutic genes, including tissue inhibitors of matrix metalloproteinases (TIMP-3) [37], nitric oxide synthase (NOS) [38] and p53 [39], which are key to neointimal formation. However, these genes could only regulate one factor contribute to restenosis following balloon dilation. CBP is known to be a powerful transcriptional coactivator, which works as functional integrators of numerous signal transduction pathways because diverse transcription factors compete for limiting amounts of CBP $[24,40]$. Previous studies have described that CBP mediates both negative and postive cross-talk between different signalling pathways [27]. Moreover, CBP could also play distinct biological functions in different enviroments and cell types. Thus, tight control over the protein level of CBP is essential for preventing the development and progression of human diseases. Although the implication of $\mathrm{CBP} / \mathrm{p} 300$ in some tumorigenesis has been recognized [41], very little has been achieved in the area of cardiovascular system. In this study, we focused on the effect of CBP on neointimal formation induced by balloon catheter injury. Our results showed that CBP was expressed in normal arterial walls, and that it was upregulated significantly after balloon injury. Meanwhile, CBP gene silencing led to a substantial
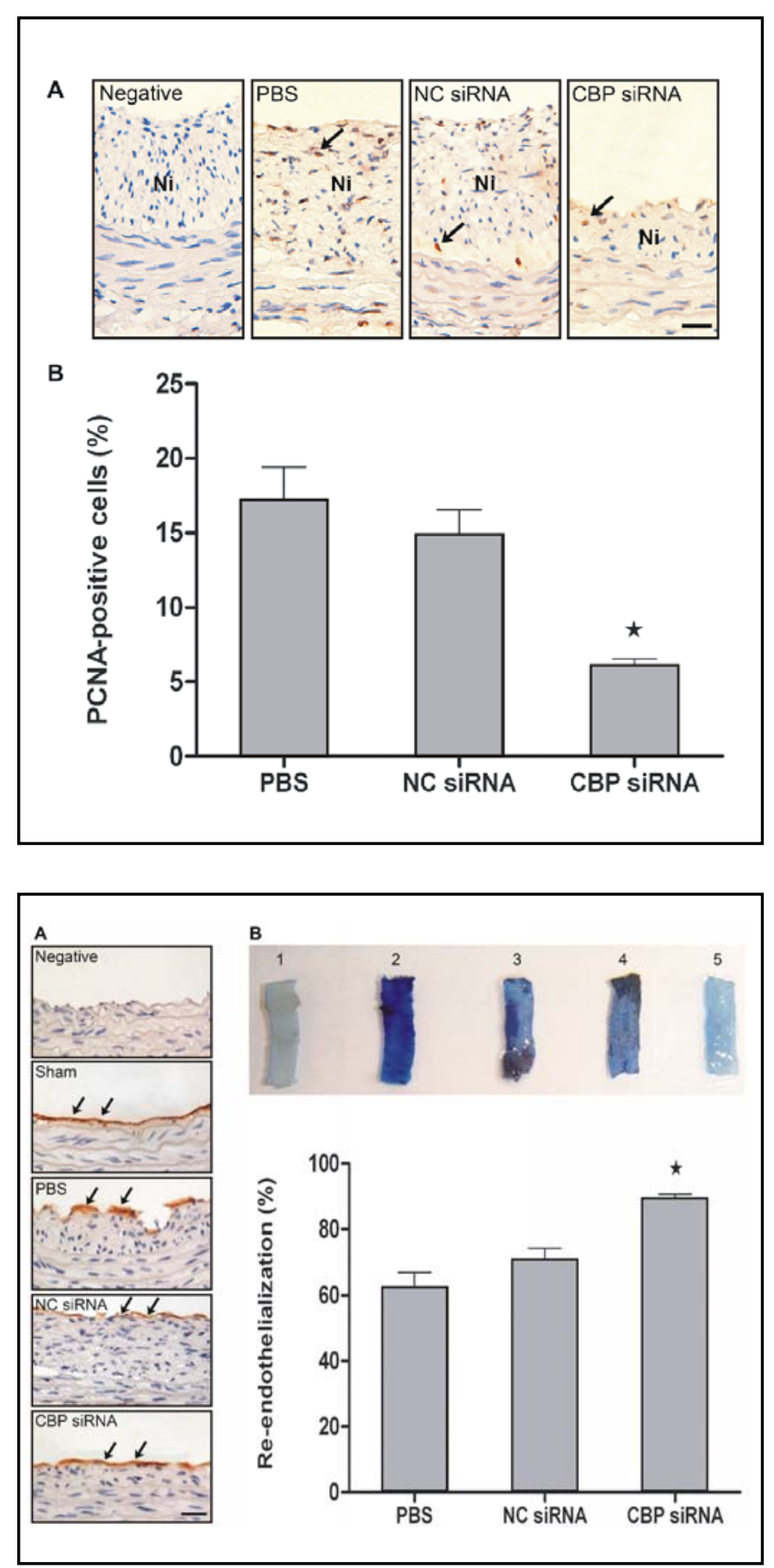

Fig. 6. CBP silencing enhanced re-endothelialization at 4 weeks after balloon injury. (A) Typical observations of endothelial cells stained by anti-CD31 antibodies in the carotid arteries. CD31-positive endothelial cells (arrows) only covered the luminal surface. Scale bar represents $25 \mu \mathrm{m}$. (B) Top: Representative Evans Blue staining photograph showing the deendothelialized (blue or dark brown) and endothelialized (white) areas. (1) non-injured artery; (2) injured artery; (3) injured artery + PBS treatment; (4) injured artery + NC siRNA; (5) injured artery + CBP siRNA. Bottom: Percent endothelial regrowth 4 weeks after balloon injury and gene delivery. Values are expressed as mean \pm SEM. $n=6$ per group. ${ }^{\star} P<0.05$ vs. NC siRNA and PBS control groups.

Yang/Jiang/Chen/Chen/Li/Xu/Wang 
inhibition effect on cells proliferation and intimal thickening. These results revealed that CBP was indeed a potential intervention target for gene therapy in cardiovascular system diseases.

Another major finding of the present study was that CBP siRNA accelerated endothelial regrowth after balloon-induced arterial injury. At 4 weeks after injury, re-endothelialization of balloon-injured arterial segments in the CBP siRNA group was significantly higher. To date, a considerable amount of strategies have successfully been investigated and employed at the treatment of neointimal formation; however, the associated delay in endothelialization may reduce the therapeutic benefit. Our data indicates that CBP knockdown plays dual roles in the treatment and prevention of restenosis.

In this study, we have also investigated the underlying mechanisms of how CBP silencing inhibits neointimal formation and promotes re-endothelialization. $\mathrm{NF}-\kappa \mathrm{B}$, as an important transcriptional factor, was regulated by CBP. The activation of NF- $\mathrm{KB}$ in the vessel wall after arterial injury has been established by several reports $[42,43]$, which could contribute to neointima formation and delayed re-endothelialization. After translocation into the nucleus, $\mathrm{NF}-\kappa \mathrm{B}$ physically interacts with CBP. In addition to CBP's ability to acetylate histones, it is also able to acetylate other proteins like transcription factors and coactivators. Previously, CBP and p300 have been shown to mediate inflammatory responses, which it achieves in part by acetylating $\mathrm{NF}-\kappa \mathrm{B}$ [44]. NF- $\kappa \mathrm{B}$ could be acetylated at multiple lysine residues by $\mathrm{CBP}$ [45]. Acetylation of these residues may lead to enhanced NF- $\kappa \mathrm{B}$ p65 transcriptional activity. Thus, the limiting CBP may efficiently regulate NF- $\kappa B$ activity. Our data clearly demonstrated that CBP silencing markedly suppressed balloon injury-induced $\mathrm{NF}-\kappa \mathrm{B}$ p65 acetylation without changing its nuclear translocation.

In summary, results from this study provide the first evidence that lentivirus-mediated RNAi targeting CBP attenuates neointimal formation and promotes reendothelialization in balloon injured rat carotid artery, which may be mainly ascribed to downregulation of $\mathrm{NF}-\kappa \mathrm{B}$ acetylation. We believe that CBP represents a powerful, new multifunction protein that provides a potential target for the treatment of occlusive vascular diseases.

\section{Acknowledgements}

This work was supported by a grant from the National Natural Science Foundation of China (No. 30770849).

\section{References}

1 Grüntzig AR, Senning A, Siegenthaler WE: Nonoperative dilatation of coronary-artery stenosis: percutaneous transluminal coronary angioplasty. $\mathrm{N}$ Engl J Med 1979;30:61-68.

- Kobayashi J: Current status of coronary artery bypass grafting. Gen Thorac Cardiovasc Surg 2008;56:260-267.

-3 Bermejo J, Botas J, García E, Elízaga J, Osende J, Soriano J, Abeytua M, Delcán JL: Mechanisms of residual lumen stenosis after high-pressure stent implantation: a quantitative coronary angiography and intravascular ultrasound 8 study. Circulation 1998;98:112-118.

-4 Suzuki J, Tezuka D, Morishita R, Isobe $\mathrm{M}$ : An initial case of suppressed restenosis with nuclear factor-kappa B decoy transfection after percutaneous coronary intervention. J Gene Med 2009;11:8991.

5 Welt FG, Rogers C: Inflammation and restenosis in the stent era. Arterioscler Thromb Vasc Biol 2002;22:1769-1776.
Egashira K, Zhao Q, Kataoka C, Ohtani K, Usui M, Charo IF, Nishida K, Inoue S, Katoh M, Ichiki T, Takeshita A: Importance of monocyte chemoattractant protein-1 pathway in neointimal hyperplasia after periarterial injury in mice and monkeys. Circ Res 2002;90:1167-1172

Simons M, Edelman ER, DeKeyser JL, Langer R, Rosenberg RD: Antisense cmyb oligonucleotides inhibit intimal arterial smooth muscle cell accumulation in vivo. Nature 1992;359:67-70.

Hao H, Gabbiani G, Bochaton-Piallat ML: Arterial smooth muscle cell heterogeneity: implications for atherosclerosis and restenosis development. Arterioscler Thromb Vasc Biol 2003;23:1510-1520.

Sousa JE, Serruys PW, Costa MA: New frontiers in cardiology: drug-eluting stents: Part I. Circulation 2003;107:2274-2279.
Daemen J, Serruys PW: Drug-eluting stent update 2007: part I. A survey of current and future generation drug-eluting stents: meaningful advances or more of the same? Circulation 2007;116:316328

Kraitzer A, Kloog Y, Zilberman M: Approaches for prevention of restenosis. J Biomed Mater Res B Appl Biomater 2008;85:583-603.

Joner M, Finn AV, Farb A, Mont EK, Kolodgie FD, Ladich E, Kutys R, Skorija K, Gold HK, Virmani R: Pathology of drug-eluting stents in humans: delayed healing and late thrombotic risk. J Am Coll Cardiol 2006;48:193-202.

Togni M, Räber L, Cocchia R, Wenaweser P, Cook S, Windecker S, Meier B, Hess OM: Local vascular dysfunction after coronary paclitaxel-eluting stent implantation. Int J Cardiol 2007;120:212-220. 
14 Indolfi C, Coppola C, Torella D, Arcucci $\mathrm{O}$, Chiariello $\mathrm{M}$ : Gene therapy for restenosis after balloon angioplasty and stenting. Cardiol Rev 1999;7:324-331.

15 Ahn YK, Kook H, Jeong MH, Ahn KY, Cho JG, Park JC, Kang JC, Kim KK: Local RAD50 gene delivery induces regression of preformed porcine coronary in-stent neointima hyperplasia. J Gene Med 2004;6:93-104.

16 Kastrup J, Jørgensen E, Rück A, Tägil K, Glogar D, Ruzyllo W, Bøtker HE, Dudek D, Drvota V, Hesse B, Thuesen L, Blomberg P, Gyöngyösi M, Sylvén C; Euroinject One Group: Direct intramyocardial plasmid vascular endothelial growth factor-A165 gene therapy in patients with stable severe angina pectoris A randomized double-blind placebo-controlled study: the Euroinject One trial. J Am Coll Cardiol 2005;45:982-988.

17 Gaffney MM, Hynes SO, Barry F, O’Brien $\mathrm{T}$ : Cardiovascular gene therapy: current status and therapeutic potential. $\mathrm{Br} \mathrm{J}$ Pharmacol 2007;152:175-188.

18 Kwok RP, Lundblad JR, Chrivia JC, Richards JP, Bächinger HP, Brennan RG, Roberts SG, Green MR, Goodman RH Nuclear protein CBP is a coactivator for the transcription factor CREB. Nature 1994;370:223-226.

19 Arany Z, Sellers WR, Livingston DM, Eckner R: E1A-associated p300 and 31 CREB-associated CBP belong to a conserved family of coactivators. Cell 1994;77:799-800.

20 Goodman RH, Smolik S: CBP/p300 in cell growth, transformation, and development. Genes Dev 2000;14:1553- >32 1577.

21 Warner DR, Pisano MM, Greene RM: Functional analysis of $\mathrm{CBP} / \mathrm{p} 300$ in embryonic orofacial mesenchymal cells. 33 J Cell Biochem 2006;99:1374-1379.

-22 Ait-Si-Ali S, Ramirez S, Barre FX, Dkhissi F, Magnaghi-Jaulin L, Girault JA, Robin P, Knibiehler M, Pritchard LL, Ducommun B, Trouche D, Harel-Bellan A: Histone acetyltransferase activity of CBP is controlled by cycle-dependent kinases and oncoprotein E1A. Nature 1998;396:184-186

23 McManus KJ, Hendzel MJ: CBP, a transcriptional coactivator and acetyltransferase. Biochem Cell Biol 2001;79:253-266.

24 Ghosh S: Regulation of inducible gene expression by the transcription factor NF-kappaB. Immunol Res 1999;19:183189
-25 Albanese C, D’Amico M, Reutens AT, Fu M, Watanabe G, Lee RJ, Kitsis RN, Henglein B, Avantaggiati M, Somasundaram K, Thimmapaya B, Pestell RG: Activation of the cyclin D1 gene by the E1A-associated protein p300 through AP-1 inhibits cellular apoptosis. J Biol Chem 1999;274:34186-34195. Avantaggiati ML, Ogryzko V, Gardner K, Giordano A, Levine AS, Kelly K: Recruitment of p300/CBP in p53dependent signal pathways. Cell 1997;89:1175-1184.

27 Matt T: Transcriptional control of the inflammatory response: a role for the CREB-binding protein (CBP). Acta Med Austriaca 2002;29:77-79.

28 Chen J, Jiang H, Xu L, Zhu LH, Wang L, Wen HZ, Hu XR: Dysregulation of CREB binding protein triggers thrombin-induced proliferation of vascular smooth muscle cells. Mol Cell Biochem 2008;315:123130 .

29 Natarajan R, Pei H, Gu JL, Sarma JM, Nadler J: Evidence for 12-lipoxygenase induction in the vessel wall following balloon injury. Cardiovasc Res 1999;41:489-499.

30 Lee YA, Cho EJ, Yokozawa T: Effects of proanthocyanidin preparations on hyperlipidemia and other biomarkers in mouse model of type 2 diabetes. J Agric Food Chem 2008;56:7781-7789.

Yang J, Yang J, Ding JW, Chen LH, Wang YL, Li S, Wu H: Sequential expression of TLR4 and its effects on the myocardium of rats with myocardial ischemiareperfusion injury. Inflammation 2008;31:304-312.

Baker AH: Designing gene delivery vectors for cardiovascular gene therapy. Prog Biophys Mol Biol 2004;84:279299.

Wright MJ, Wightman LM, Lilley C, de Alwis M, Hart SL, Miller A, Coffin RS, Thrasher A, Latchman DS, Marber MS: In vivo myocardial gene transfer: optimization, evaluation and direct comparison of gene transfer vectors. Basic Res Cardiol 2001;96:227-236.

34 Rutanen J, Rissanen TT, Markkanen JE, Gruchala M, Silvennoinen P, Kivelä A, 44 Hedman A, Hedman M, Heikura T, Ordén MR, Stacker SA, Achen MG, Hartikainen J, Ylä-Herttuala S: Adenoviral cathetermediated intramyocardial gene transfer using the mature form of vascular $>45$ endothelial growth factor-D induces transmural angiogenesis in porcine heart. Circulation 2004;109:1029-1035.
Bartosch B, Cosset FL: Strategies for retargeted gene delivery using vectors derived from lentiviruses. Curr Gene Ther 2004;4:427-443

Costello E, Munoz M, Buetti E, Meylan PR, Diggelmann H, Thali M: Gene transfer into stimulated and unstimulated T lymphocytes by HIV-1-derived lentiviral vectors. Gene Ther 2000;7:596-604.

Akowuah EF, Gray C, Lawrie A, Sheridan $\mathrm{PJ}$, Su CH, Bettinger T, Brisken AF, Gunn J, Crossman DC, Francis SE, Baker AH, Newman CM: Ultrasound-mediated delivery of TIMP-3 plasmid DNA into saphenous vein leads to increased lumen size in a porcine interposition graft model. Gene Ther 2005;12:1154-1157.

West NE, Qian H, Guzik TJ, Black E, Cai S, George SE, Channon KM: Nitric oxide synthase (nNOS) gene transfer modifies venous bypass graft remodeling: effects on vascular smooth muscle cell differentiation and superoxide production. Circulation 2001;104:15261532

Wan S, George SJ, Nicklin SA, Yim AP, Baker AH: Overexpression of p53 increases lumen size and blocks neointima formation in porcine interposition vein grafts. Mol Ther 2004;9:689-698.

Janknecht R, Wells NJ, Hunter T: TGFbeta-stimulated cooperation of smad proteins with the coactivators $\mathrm{CBP} / \mathrm{p} 300$. Genes Dev 1998;12:2114-2119.

Karamouzis MV, Konstantinopoulos PA, Papavassiliou AG: Roles of CREB-binding protein $(\mathrm{CBP}) / \mathrm{p} 300$ in respiratory epithelium tumorigenesis. Cell Res 2007; 17:324-332.

Ialenti A, Ianaro A, Maffia P, Carnuccio R, D'Acquisto F, Maiello FM, Di Rosa M: Role of nuclear factor-kappaB in a rat model of vascular injury. Naunyn Schmiedebergs Arch Pharmacol 2001;364:343-350.

Jones WK, Brown M, Wilhide M, He S, Ren X: NF-kappaB in cardiovascular disease: diverse and specific effects of a "general" transcription factor? Cardiovasc Toxicol 2005;5:183-202.

Hoberg JE, Popko AE, Ramsey CS, Mayo MW: IkappaB kinase alpha-mediated derepression of SMRT potentiates acetylation of RelA/p65 by p300. Mol Cell Biol 2006;26:457-471.

Saha RN, Jana M, Pahan K: MAPK p38 regulates transcriptional activity of NFkappaB in primary human astrocytes via acetylation of p65. J Immunol 2007;179:7101-7109. 